Morgan J \& Sarah P, Researcher Safety? Ethnography in the Interdisciplinary World of Audit Cultures, Cultural Studies - Critical Methodologies (Volume 18, Issue 6), pp. 400-409. Copyright () 2017 SAGE Publications. Reprinted by permission of SAGE Publications

\title{
Researcher Safety?: Ethnography in the Interdisciplinary World of Audit Cultures
}

\section{Acknowledgements/Credits}

The ethnographic research discussed here was undertaken by Jennie Morgan in collaboration with Sarah Pink and Andrew Dainty. Our first thanks go to the people who gave up time during their busy working lives to participate in this project, and help arrange our research placements. Without their collaboration this article would not have been possible. The research was conducted within the 'Management of OSH in Networked Systems of Production or Service Delivery: Comparisons between Healthcare, Construction and Logistics' project, funded by the Institution of Occupational Safety and Health (IOSH), in their Health and Safety in a Changing World programme. We are grateful to IOSH, and particularly to Robert Dingwall and Jane White for their support of our work. The project was based at Loughborough University, UK, and we are grateful for the collaboration and support of Alistair Gibb and our team of colleagues and co-researchers.

\author{
Authors \\ Dr Jennie Morgan, University of York, UK \\ Professor Sarah Pink, RMIT University, Melbourne Australia
}

\section{Funding Information}

The research was conducted within the 'Management of OSH in Networked Systems of Production or Service Delivery: Comparisons between Healthcare, Construction and Logistics' project, funded by the Institution of Occupational Safety and Health (IOSH), in their Health and Safety in a Changing World programme. 
Corresponding Author: Jennie Morgan, Department of Sociology, University of York, Heslington, York, YO10 5DD, UK jennie.morgan@york.ac.uk

\title{
Researcher Safety?: Ethnography in the Interdisciplinary World of Audit Cultures
}

\author{
Abstract \\ Anthropologists intermittently reflect on the danger and risk that ethnography can involve. \\ Here, we advance this question in a contemporary research environment where the regulatory \\ logics of occupational safety and health (OSH) encroach increasingly on anthropological \\ practice through institutional research governance. We draw on our research into workplace \\ OSH in the construction, healthcare, and logistics sectors - a research field dominated by \\ behavioural theories that support the preventative logics of OSH regulation. Taking an \\ autoethnographic approach, we explore how researching in potentially dangerous \\ environments requires ethnographers to learn how to be safe through others' situated safety \\ logics and through those of researcher safety. It is, we argue, through these engagements with \\ the improvisory ways that workers generally, and researchers specifically, engage with safety, \\ that another set of inconsistencies between OSH preventative logics and our anthropological \\ understanding of how ethnographic knowing emerges become visible.
}

\section{Keywords}

Autoethnography, audit cultures, researcher safety, regulation, improvisation, reflexivity, anthropology 


\section{Researcher Safety?: Ethnography in the Interdisciplinary World of Audit Cultures}

\section{Introduction}

Researcher safety in ethnographic fieldwork is increasingly foregrounded through the discourses and systems of occupational safety and health (OSH), encountered through institutional guidelines and protocols. Such guidance and policy has framed the transdisciplinary travels of ethnography. Working across disciplines, ethnographic researchers are urged - through University lone worker policies, risk assessment forms, or ethical review - to plan for ensuring their safety when undertaking fieldwork. The rise of $\mathrm{OSH}$ as framing ethnographic practice is related to the broader institutionalization of research through regulatory frameworks of "anticipatory audit" (Strathern, 2000, p. 295). OSH governance seeks to anticipate and safeguard against future harm to selves, others, and organizations through systematic guidance.

Ironically, for anthropologists it does so through the application of frameworks that are informed by disciplinary behavioural theories that our own critical corpus contests. Discussions emerging in other disciplines, including examples in health care (Dickson et al., 2008) and social work (Ferguson 2009, 2010), also contest these frameworks - particularly in the setting of the lone home visit for both practitioners and fieldworkers. They highlight a mismatch between institutional OSH guidance and actual practical risks. To contend with this regulatory context as ethnographers therefore means keeping a foot in the (interdisciplinary) field of safety research, from where we might contest such frames. This is a field where, Helen Lingard (Lingard et al., 2015) outlines, "Hale and Borys (2013) identify two approaches to achieving workplace H\&S” (p. 741). The first is an anticipatory "“top-down' approach which emphasizes enforcing workers' compliance with rules. When workers make errors these are attributed to individual behavioural issues, for example, laziness, 
complacency, or a tendency to take risks (Hayes and Hopkins, 2014)" (p. 741). Hale and Borys nevertheless set out an alternative approach to worker safety. Rules are considered "dynamic" and "situated", and workers "experts whose competence enables them to adapt rules to suit their particular situation" (cited in Lingard et al., 2015, p. 741). This approach is more aligned to ours. It therefore offers a reference point for a critical anthropological contribution, which supports revisionist stances in the interdisciplinary field of OSH literatures.

We do not dispute that "advance preparedness" (Bloor et al., 2007, p. 4), or seeking to foresee potential hazards and establish parameters for appropriate action, can be an effective route towards ensuring researcher safety. This may be especially necessary in contexts where fieldworkers operate at the boundaries between the "safe" and "unsafe". However, a critical understanding of how transdisciplinary anticipatory logics of OSH encroach on ethnographic practice is needed.

To contribute to this conversation in this article, we first draw on anthropological and critical OSH research to offer alternative methodological and conceptual starting points for approaching researcher safety. We then develop an autoethnographic analysis of our experience undertaking applied ethnographic research across healthcare, logistics, and construction organizations. This was within a transdisciplinary UK-based project which addressed the question of improving workplace OSH. Through a discussion of how Jennie came to "know how" to research (safety) safely in these contexts we show how she blended anticipatory OSH logics with contingent, personal, and improvisory ways of knowing. Finally we engage these insights to reflect on the implications of regulatory OSH frameworks for ethnographic research both within and beyond anthropology.

When such frameworks are critiqued through ethnographically informed anthropological theory our work cannot escape being imbued with a transdisciplinary 
challenge. We argue that by harnessing the "antagonistic" (Barry et al., 2008) potential of transdisciplinary work, anthropologists have a critical role to play in a revisionist rewriting of OSH frameworks to benefit ethnographers working across disciplines.

\section{OSH and its Anticipatory Logics}

Anthropological analysis of academic "audit cultures" (e.g., Strathern, 2000) shows how anticipatory logics are now part of how academic life is experienced, often through the bureaucratization of academic practice and research governance (e.g., Shore and Wright 1999, 2015). The codification of research ethics and institutional review boards - often regarded as emblematic of this broader regulatory research environment - have come under particular scrutiny (Lederman, 2007; Macdonald, 2009; Meskell and Pels, 2005). Such accounts express concern about the framing of ethnographic practice through transdisciplinary ethical codes. As Macdonald (2009, p. 81) summarizes, key anthropological concerns focus on: codification holding the potential to externalize ethics in bureaucratic process (rather than internal to the discipline and research relationships), and if pan-disciplinary ethics governance modelled on practices developed in other disciplines (such as the biomedical) can accommodate ethnographic research.

The rise of OSH discourses and systems is similarly part of a wider turn towards "anticipatory audit" within university and research governance (at least within the United Kingdom context where our research was undertaken). Like the formalization of ethical review through biomedical criteria, OSH may be interpreted as intended to (partly) facilitate the travel of ethnography by covering its application across a wide range of fieldwork and disciplinary contexts. Ethnography becomes detached from anthropological codes, training, and practices to draw instead on procedures and systems informed by other disciplines including behavioural theories. It is perhaps not surprising that OSH (a specific form of 
anticipatory audit) has accompanied the travels of ethnography given, as Barry and colleagues (2008) argue, that accountability is a guiding logic of contemporary transdisciplinarity.

Early mention of OSH was made by anthropologist Nancy Howell in 1986 (in Sluka, 2012, p. 283). Yet, to our knowledge, the implications of OSH regulatory frameworks and anticipatory audit for researcher safety in ethnographic fieldwork (unlike the ethical review modelled on biomedical criteria introduced above) have not generated sustained debate within anthropology. This is despite nascent conversations about the implications of OSH for practitioner and/or researcher safety emerging in other fields, including health and social work studies. Anthropologists have considered how they have coped with dangerous or violent fieldwork situations. Yet they often do so through ethnographic reflexivity rather than in relation to OSH (e.g., Moreno, 1995). More recently, a growing literature across anthropology (e.g., Samimian-Darash and Rabinow, 2015), human geography (e.g., Adey and Anderson, 2011; Anderson, 2010), and safety research (e.g., Hale and Borys, 2013; Powell at al., 2014) has begun to engage critically with conceptual categories and empirical realities of "anticipation", "risk", and "uncertainty". Such literatures provide an invigorating critical context through which to engage with questions of researcher OSH.

While we need to have ways of ensuring that people (including researchers) stay safe at work, as a regulatory framework OSH procedures tend to create a logic that cannot acknowledge or harness the creative potential of uncertainty (Pink and Akama, 2015). OSH frameworks (like those of ethics) construct possible harmful scenarios along with preventative procedures for their avoidance. Knox and Harvey (2011) describe, based on their ethnographies of road building projects in Latin America, how OSH is concerned with the “anticipation of harm"” in situations of uncertainty (p. 145). The conclusion of OSH logic thus is to supress uncertainties. It is challenging for OSH to welcome the unknown, precisely 
because this would not account for the unsafe. Yet, ironically, the quest to obliterate the unknown could create further dangers, since it is theoretically possible that a reflexive awareness of what we do not know could be safer than the "truths" that we think we know. Revisionist OSH approaches which seek not only to predict and plan for risks but to better support researchers managing and responding to hazards as they unfold in and through ethnographic practice are sorely needed.

As Strathern (2000) points out for ethics audits, OSH regulation "pushes the exploratory, indeterminate and unpredictable nature of social relations (between ethnographer and his or her third party) back onto a 'point of production', with the ethnographer as initiator" (p. 295). Like Strathern's (2000) “ethics in advance, of anticipated negotiations", we suggest that OSH in advance also "belittles the creative power of social relations" (p. 295). For instance, in their review of literature and professional guidance for qualitative researchers, Bloor and colleagues (Bloor et al., 2007) identify physical risk (e.g., injury), emotional risk (e.g., feelings of isolation), and gender risk (e.g., harassment). They suggest that planning and preparation through risk assessment is key to avoiding harm (p. 17). Sluka (2012) also concludes that "to a substantial degree the dangers faced by anthropologists in their fieldwork can be mediated through foresight, planning, and skilful manoeuvre" (p. 284). Such statements echo the logic of prevention and the mitigation of risk that depends on the construction of abstract future certainties introduced above.

Yet, the critical literatures cited above, and our fieldwork experiences, indicate that following the regulated anticipatory logics of OSH is not the only way of enacting safety in research environments that have qualitatively or statistically been characterized as “dangerous". In recent scholarship, likewise, an explosion of risk management to respond to futures which (ultimately) can never entirely be known in advance is increasingly being queried through calls for a new "politics of uncertainty" (Power, 2004). Anthropologists here 
(Powell et al., 2014; Samimian-Darash and Rabinow, 2015) argue for shifting analytical and applied focus from controlling risk to managing uncertainty (Samimian-Darash and Rabinow, 2015 , p. 5). Where this connects with the field of OSH management research is in relation to the desire to develop what Hale and Borys (2013), who are critical of top-down OSH regulation, call “model 2" engagement with regulated OSH. A model 2 approach acknowledges the productive role that the practically informed, creative adaptation of safety rules can play in the ongoing monitoring and design of effective OSH. When read together these literatures from different disciplines (anthropology and safety research) problematize risk management as a dominant form of anticipatory audit for engaging with uncertainty. They argue for the need to recognize, account for, and harness the creative potential of not knowing, and the experiential, emotional, technical, and systematic learning that arises through encountering uncertainty. This, we argue, is where an anthropological and ethnographically informed perspective can make a useful interdisciplinary intervention in safety research. We return to this below by discussing the potentials and pitfalls of OSH for ethnographic research. First, we account for how such a perspective can be generated through an autoethnographic approach to safety in ethnographic practice.

\section{Reflecting On Autoethnography: Learning and Knowing Safety}

The term autoethnography is used in multiple ways including distinctions made between “evocative or emotional" and "analytical" autoethnography (Anderson, 2006). It is beyond the scope of this article to describe in detail these different approaches but rather we emphasize that "self observation" (Hayano, 1979) typifies autoethnography as a process and product of drawing on personal experiences, emotions, thoughts, and feelings to better understand those of others. It has been argued that what characterizes different forms of autoethnography is "the emphasis placed on the study of others, the researcher's self and 
interaction with others, traditional analysis, and the interview context, as well as on power relationships" (Ellis et al., 2011). By drawing on the ways that Jennie's perceptual and practical approach to her safety were changed through (and deeply embedded in) the fieldwork process our research may also thus be considered a reflexive ethnography. Some consider this to be a specific type of autoethnography (Ellis et al., 2011).

One approach that illustrates this reflexive emphasis is to understand autoethnography as "an approach to research and writing that seeks to describe and systematically analyze (graphy) personal experience (auto) in order to understand cultural experience (ethno)" (Ellis et al., 2011). While we seek to analyze Jennie's personal experience, our approach is also deeply informed through our shared research interactions. Indeed, choosing to co-author this article communicates how our reflexive autoethnographic approach was a collaborative endeavour undertaken as part of a bigger team project. Self-reflexivity might seem paradoxical to such an approach. Yet "collaborative (CAE) autoethnography" (Chang et al., 2013) is a methodology that is gaining momentum. CAE seeks to counter (what some have argued is a trap of) an inward focus typical of more narrative and evocative forms of autoethnography (Chang et al., 2013). CAE directs analysis of self-inquiry towards broader cultural understanding and shared meaning-making. In our work, ongoing critical dialogue between the authors (and other team members) enabled us to apply to our analysis insights gained from other research, disciplinary, literature, and professional contexts. In doing so, questions were asked about Jennie's reflections that revealed nuance about the contexts under study that she would not necessarily have recognized alone. For example, a crucial turning point in our fieldwork arrived when Sarah encouraged Jennie to try to identify "quiet safety" (Pink and Morgan, 2013), or the taken-for-granted and easily overlooked techniques that she suspected (from her research elsewhere) workers would likely share to help her take care in 
unfamiliar workplaces. We also looked to our reading of anthropological theories of learning and knowing to further develop our collaborative autoethnographic approach.

Ethnography has been understood as a "learning phenomenon" (Evans, 2012, p. 98). Anthropological scholarship on apprenticeship (Grasseni, 2009; Harris, 2007; Marchand, 2010) enables us to conceptualize learning as an ongoing practical activity situated in specific material, social, temporal, affective, and sensory environments. By understanding ethnographic apprenticeship as "both a mode of learning and a field method" (Marchand, 2010), we have used autoethnographic reflection on learning as a "method" for understanding how OSH is made to happen in particular workplace settings and how ethnographic apprenticeship becomes a "mode of learning" that is itself generative of researcher safety vis$\grave{a}$-vis the acquisition of practical and perceptual skills. Such an approach involves seeing anthropology as Ingold (2011b) puts it "not a study of at all, but a study with" people, whereby "Immersed with them in an environment of joint activity, they learn to see things (or hear them, or touch them) in the ways their teachers and companions do" (p. 238). From this perspective, apprenticeship can be seen as a process of learning through which individuals develop a perceptual awareness of environmental properties and the possibilities for action that these afford (Ingold 2011a, p. 37). By emphasizing that knowing is an incremental and contextually contingent process, this definition of apprenticeship resonates with the creative and responsive dimensions of ethnographic research that (we have argued) problematize OSH anticipatory logics. Acquiring this know-how is a process of what Ingold (2011a) calls "enskilment" whereby learning is not the transmission of discrete pieces of information, but an ongoing practical, bodily, and multisensory encounter with the world through which practitioners become skilled in perceiving (paying attention) and responding (attuning their practical actions) to its emergent qualities (p. 37, see also p. 416). Self-reflection - or taking what one has learned to move forward while reflecting on earlier experience (Ingold, 2013, p. 
3) - is crucial to studying with and learning from others. We now take this up through our discussion of Jennie's autoethnographic apprenticeship in safety. We highlight four specific aspects of researcher safety: learning, knowing, doing, and improvising.

\section{'Walking On Steel': An Autoethnography of OSH}

During 2012 and 2013, Jennie spent six weeks at a Health Service Trust with a communitybased team; five weeks at a retail warehouse-depot with customer deliveries workers; and five weeks across two different construction sites. This fieldwork was part of a bigger research project undertaken with a team of interdisciplinary colleagues. It focused on the applied question of how to improve workplace OSH by generating better understanding of how OSH knowledge is engaged by workers. Informed by the anthropological theories of knowing we outlined above, and responding to working in an interdisciplinary and applied context, our short-term fieldwork used interventional methodologies designed to provide different analytical, conceptual, and methodological entry points to those of more conventional longer-term engagements with other peoples' lives. Specifically, in addition to more traditional interview and observational techniques, we used walking, re-enactment, and apprenticeship methods to create "intensive encounters" (Pink and Morgan, 2013) with participants. These were intended to understand their perspectives through shared discussion, reflection, and collaboration rather than simply through observation. Reflecting on Jennie's experiences during and after the fieldwork was fundamental to our understandings of her own and others' performances of OSH in these contexts. This included an ongoing almost daily dialogue with Sarah, and our colleague Sociologist Andrew Dainty, as well as deep autoethnographic reflection. In this context, this meant a shift in sustained attention from others to our own safety. 


\section{First Encounters}

Practices of regulated-OSH played a necessary role in informing Jennie's personal safety. With our colleagues at the University we sought out frameworks to support our researcher safety processes, including "guidelines for lone working". Additionally, with team members we developed a shared process for "safeguards" by including mobile phone check-ins. These safeguards, which resonated with those used by our participants who undertook lone and mobile work (Pink et al., 2014a), created feelings of "backup" by connecting Jennie with the research team when working remotely.

It was also a requirement from the partner organizations that were our research sites that Jennie undergo industry and site-specific OSH-training. This included learning what personal protective equipment (PPE) she needed to wear (e.g., safety boots, high visibility vest, gloves, goggles, and hard-hat in the construction sector), and participating in their organizational training schemes. Construction industry gate-keepers required Jennie to gain a visitor level professional OSH-training card through the UK-based CSCS scheme (http://www.cscs.uk.com/). She was also inducted in site rules and regulations. Logistics and healthcare managers and supervisors introduced Jennie to workplace protocol by explaining things like: the need to wear PPE, fire and security procedures, provisions for signing in and out, acceptable mobile phone usage, and sticking to dedicated walkways in car parks, yards, and the warehouse floor. Sometimes these rules sat ambiguously with the University OSH regulations. For example, it was procedure at construction sites and the logistics warehouse for mobile phone usage to not occur beyond dedicated areas (e.g., canteens, offices, mobile phone stations), whereas our internal team safeguards stipulated that Jennie should carry with her and have switched on at all times a mobile phone.

This guidance alerted us to what Jennie might expect to encounter at the fieldwork sites, equipped us with strategies to respond to hazards, and constructed an infrastructure 
intended to assist her in the event of a safety issue. Moreover, practising regulated-OSH

enabled Jennie to make her (newly acquired) OSH-competency visible and (in the construction industry through card schemes) transferrable when she moved between sites. However, it was evident - through autoethnographic reflection - that this formal competency was not the only element required to "know how" to "do" safety in contextually appropriate ways. Elsewhere we have theorized our research sites as emergent environments where workers were confronted with continuously changing situations (Pink et al., 2015). Construction sites continually change materially and socially as buildings progress, subcontractors come and go, and according to weather conditions. The homes that community healthcare and logistics customer delivery workers go into are unpredictable in terms of their social, material, sensory, and affective features. During the fieldwork, navigating uncertainty towards safety characterized not only our participants' experiences, but also Jennie's. The intense demands of this task (manifest through feelings of "exhaustion" and being "overwhelmed") made very immediate the consideration of how best she should take care in these scenarios when to get it wrong might put herself or others at risk, often at levels of detail that could not be covered in regulatory documents. It is to some specific examples of what could go wrong, and learning how to recognize what the actual risks on sites were, that we now turn. These involved yet were not limited to physical (e.g., trips, slips, or strains walking on uneven construction site ground, or being hit by machinery or equipment); health (e.g., catching an illness from a healthcare home visit, or breathing in hazardous substances like dust on a construction site); and emotional (e.g., the stress or isolation of lone field-working).

\section{Recognizing Risk}


OSH frameworks prepared us to identify and respond to research risks. However, learning how to recognize risk was also generated from Jennie's interactions with participants, and through her ongoing practical engagement with the material, spatial, sensory, and social contingencies of these workplace environments. Returning to our understanding of ethnographic learning we outlined above, this may be considered a form of apprenticeship by learning how to enact safety in contextually appropriate ways. Jennie partook in shared activities with participants (where appropriate to do so), learnt from their expert site-based knowledge, and sought to acquire similar practical and perceptual skills needed to navigate being in these work contexts safely.

In healthcare, for example, she came to perceive and attune her actions to the unseen health threat of microbes. Workers encouraged her to mimic their routines and material culture of hand hygiene by carrying on her body and using disinfectant hand-gel. While Jennie did not have any actual (or hands on) contact with patients during community visits, this encouraged her to consider the risk of infection from contact with the material environment of the home visit in a way she had not previously considered (Pink et al., 2014b). Beyond perceiving potential yet invisible danger, fieldwork also revealed how recognizing risk was a multisensory, bodily, and affective experience. Author 1 also had to learn how to hear, smell, feel, and sense safety as research participants did.

For instance, initially she felt unease from, and was easily distracted by, the noise encountered on building sites, which was heightened by the embodied sensation of vibrating equipment, machinery, and vehicles. Yet, again guided by her interactions with participants, the varied sounds of building sites soon began to take on an everyday ambient quality. Jennie came to associate sound (and particular noises) with feeling and knowing herself to be safe. Listening to a bricklayer's jobsite radio created a sense of a defined workspace in an otherwise vast and complex site, while on another site she was guided to listen for whistles 
being blown which signalled that cranes were being lifted overhead. Considering these changing perceptions revealed how noise was part of specific sensory-affective working environments, and that it was directed formally and informally towards achieving safety on site. For Jennie, noise alerted her to potential dangers, helped focus her attention by defining discrete work spaces in otherwise distracting and overwhelming sites, and encouraged us to consider how construction sites are made to feel sensorially and affectively "right" for workers (including researchers).

\section{Doing $\mathrm{OSH}$}

Navigating boundaries between the safe and unsafe did not only require Jennie to develop skills in perceiving risk. She also had to learn how to do safety, or acquire the necessary techniques, skills, and competencies to research (safety) safely. Returning to our argument that autoethnographic reflection is a form of apprenticeship, one of the key research methods we used on site was walking. Walking enabled us to know through a process of what Ingold (2013) talks about as being “active following, of going along” (p. 1). Jennie was given guided tours of construction sites, was chaperoned by supervisors and managers, and experienced moving through other peoples' homes with logistics and healthcare workers. As she walked with participants who showed and told her about sites while she asked questions, wrote notes, and (where it was appropriate) took photographs, the embodied experience of these sites provided a reflexive opening that helped Jennie to consider her own and others' safety. The theoretical basis for the guided walking tour using visual methods (video, photography) - or "walking with" research participants - is well established as a method that reveals sensorial aspects of experience and place-making (Pink, 2007). Walking with participants was especially effective in the context of our research because it provided an opportunity to partake in a shared activity where participants (often) self-consciously "taught" 
Jennie about the material, spatial, sensorial, and social properties of sites. They instructed how she should (or should not) respond in ways that would ensure her safety. For example, as the vignette below recounts, when construction site workers took Jennie on walking tours they were able to show her the scope and scale of their work, associated safety risks, and OSH-strategies in ways that surpassed their verbal descriptions at meetings and audiorecorded interviews:

Walking tours on building sites usually began the same way. My guides imparted a regulated OSH-practice by checking and/or issuing me with mandatory PPE; telling me about sign-in protocol; pointing out visual communicators to identify risk (daily hazard boards); and instructing me to keep within regulated safe walkways for accessing sites. Equipped with these procedures we would then walk through the sites, and during these tours (which lasted from thirty minutes to several hours) they assisted me to recognize the people, activities, materials, spaces, and sounds that characterized the site, and helped me to understand the scope, scale, and boundaries (material as well as organizational) of the workplace environment. For example, commenting while we walked how "he works for us, he doesn't "or "we're building these houses, not those ones". Additionally, my guides shared tips for how I should take care when walking; helping me to identify slip or trip hazards when moving over uneven terrain or in the rain. During one "walk around" a trade supervisor noticed I was struggling to keep up with his pace when walking across latticed steel reinforcing bars, and asked (in what I interpreted to be a joking manner) "do you feel safe?" He then instructed me in his technique for the "right" way of walking by telling and showing me how to stand only on the top bars which were stronger than those beneath, and to direct my feet in a way which would lessen the risk of them slipping through gaps. He explained that he had likewise learnt this technique by watching others when he had started working in the trade, and encouraged me to observe how his workers moved because they too were using this method. Walking with this supervisor helped me to start attuning my embodied actions in ways that enabled me to both "feel" and "be" safe on site. (Jennie, fieldnote)

As this vignette begins to illustrate, walking with participants was a means of representing OSH (or describing and showing the researcher hazards) and experiencing safety (or encouraging the researcher through techniques of mimicry and instruction to acquire new embodied, practical, and perceptual skills). This experience of walking with workers was crucial to how Jennie learned to be safe on the construction site. Although she had passed the 
institutional OSH-requirements participants did not assume that she would necessarily know how to take care in this environment. Guided by her hosts, she acquired a perceptual and embodied awareness of potential hazards and new practical skills to navigate these. Moreover, through repeatedly walking with others, she came to appreciate that ensuring her own safety would require a complex blending of formalized OSH (e.g., sticking to safe walkways or wearing PPE) with tacit elements of everyday practice enacted through her response to the worksite as corporeal, sensory experience. This included adapting and adjusting her actions (walking style and gait) to material, spatial, and even climatic contingencies. Moreover, across the worksites we researched, Jennie mimicked the actions of others to ensure her own OSH. For example, after experiencing minor back strain when getting out of the delivery vans, she copied logistics workers to (as they instructed) "step down" using cab steps and a handhold (rather than "jumping" without any support). She also adapted her safety boots by adding extra cushioning through wearing two pairs of socks and an insole (a "tip" learned from another worker). During a community healthcare visit she copied a nurse by removing her shoes to perform OSH in relation to householders' domestic routines (Pink et al., 2015).

\section{Improvising Towards Safety}

Jennie's experiences revealed the kinds of everyday, mundane, and ongoing decisions and actions that fall outside the scope of what the institutional frameworks that regulate safety (typically) account for. Yet, were evidently crucial for her OSH-performances on site. Micropractices - including where to position ones feet on steelwork or how to adapt safety boots so that they are comfortable - illustrated what we have called "quiet" (or mundane and everyday elements of) safety (Pink and Morgan, 2013). Jennie's safety was continuously negotiated in contexts and relations of uncertainty by bringing together regulated (or forward looking 
anticipatory) OSH with ways of knowing that were contingently situated - and indeed generated from - the research process itself.

Given these insights, it is not surprising that Jennie's fieldwork experiences revealed a need to adapt her practice in response to the material, social, affective, and sensory features of workplace environments, and to the institutional-OSH guidance that framed our research activities. In this sense, like the research participants we collaborated with, she became an active participant in designing her own OSH by improvising towards safety. For instance, to negotiate the inconsistency we introduced above between University OSH frameworks and construction site mobile-phone policy, she carried a phone in her pocket that was switched on yet turned to silent so that she could ignore incoming calls but remain connected to the research team. Adding to this complex ecology of OSH, she did not carry her work mobile but her personal smartphone. There were some key reasons for this. It was physically difficult to carry two mobile phones; for security she did not want to leave her smartphone in site lockers or office spaces; her personal phone had numbers for family and friends with whom she could check in with when conducting fieldwork out of standard working hours; she was technically more competent using her personal phone; and, unlike the basic work model, her smartphone had email and internet capability which was important because digital communication was how Jennie - a lone and mobile fieldworker - maintained contact with the research team. To navigate competing institutional OSH frameworks, Jennie had to adapt and improvise mobile phone use in ways similar to the improvisations we found amongst construction workers (Pink et al., 2014a). Such insights foreground the complexities of a seemingly mundane, taken-for-granted, and straightforward aspect of workplace OSH. By selecting this example we foreground exactly the kinds of everyday, ongoing decisions that while the stakes may not be as high as more risky areas of practice - are essential for 
maintaining safety. Given that they are usually less highly regulated they are also potentially open to vagaries.

\section{From Autoethnography to Researcher Safety: The Potential of a Critical Approach}

The four aspects of researcher safety (learning, knowing, doing, and improvising) focused on above bring together formal and informal ways of navigating safety in places of work. These are characteristic of both our fieldwork and our research participants' experiences in healthcare, logistics, and the construction industry. Our autoethnographic analysis has enabled us to reflect on the researcher-safety by explicitly turning our research questions about how people "know how" to work in healthy and safe ways back onto our own ethnographic practice. Such autoethnographic reflection was also fundamental to Jennie's safety in these fieldwork sites - in that her safety was inextricable from that of the research participants and environments that she moved in and through.

This understanding of the inextricability of the ethnographer's experience from that of the people and processes that she is investigating connects to wider anthropological debate concerning how ethnographic knowing is produced, and the form that it takes. In our fieldwork, knowing was a collaborative, incremental, and creative process as Jennie came to do OSH through her practical, embodied, affective, and sensorial interactions and improvisations. The understandings of our own and others' OSH that emerged from these autoethnographic reflection are a form of knowledge that is emergent and continually being (re)formulated in response to the contingencies of specific fieldwork contexts; or what Ingold (2011b) calls "storied knowledge". We do not imply that this is specific to autoethnographic approaches, but rather that it is heightened through reflexive approaches and especially (as this article illustrates) knowing through apprenticeship. This is because, as Ingold (2011b) proposes, people (including, we would add, ethnographers working across disciplines) know 
through practice, or "an ongoing engagement, in perception and action, with the constituents of their environment" (p. 159).

Understanding knowledge as "storied" contrasts with theories of learning and knowing embedded in the certainty-seeking logics of institutional risk management; a manifestation of "anticipatory audit" (Strathern, 2000) that increasingly frames contemporary work practices including academic research. Indeed, for researcher safety, a storied knowledge perspective challenges these dominant forms of generalized and abstracted OSH. As we have accounted for in our introduction, there have been some steps towards revising this agenda. For instance, Bloor and colleagues (2007) have suggested that "inside" and "outside" perspectives on hazard might differ, and that research governance and risk assessments should therefore use "on-the-ground experience, rather than reliance on generalised expectations" (p. 8). However, a storied knowledge perspective rooted in anthropological theory takes us further. It suggests that there is a need not only to integrate sensitivity to local research settings into safety protocols and procedures, but to acknowledge and use the creative potential of the uncertain and unexpected to design new approaches to safety and its management. The implication of such understandings is that uncertainty cannot be avoided through tighter and increased regulation. Indeed (as hinted at earlier) it may actually work to be counter-productive and potentially create harm. Instead, in the context of researcher safety, we argue for the cultivation of an anthropologically-theorized reflexive awareness of what we do not know and of how we might ongoingly and creatively respond through our research practice to such uncertainty. It is beyond the scope of this article to set out precisely what these new approaches would entail. Yet we suggest a key challenge for research governance and project design is to better support researchers to manage - and respond to emerging challenges and risks - in ways that are directed towards rather than away from safety. This is because we recognize that although we focus in this article on how 
autoethnographic apprenticeship was used to achieve safety, techniques like mimicry might equally be a form of risk-taking directed to less-safe ends like "short cuts" or "work arounds." By responding to this challenge, it is our hope that anthropologists may play a formative role in a generating a revisionary applied scholarship calling for a reform of OSH frameworks that would benefit ethnographers working within as well as outside of the discipline.

\section{Conclusion}

In this article we have explored the issue of researcher safety through an autoethnographic reflection on fieldwork practice undertaken as part of an OSH research project. We revealed mundane but still complex activities, decisions, and experiences that regulated-OSH (typically) does not acknowledge, yet which were integral to achieving researcher safety in our research contexts. In doing so, we highlighted a disjuncture between how researcher safety is practiced through anthropologically-informed ethnographic fieldwork, and how ethnography is increasingly framed through institutionalized OSH-discourses accompanying its transdisciplinary travels. Logics of "anticipation" and "preparedness" are perceived as underpinning a vast spectrum of contemporary institutional and social contexts from disaster management (Adey and Anderson, 2011) to heritage conservation (Harrison, 2013). This is especially true of the neoliberal University that many ethnographers work in, and in which OSH (we hold) is symptomatic of the rise of "audit cultures" and associated technobureaucratic manifestation of new forms of governance and power (cf. Shore and Wright, 2000, p. 57)

There is however a growing questioning of the dominance of such anticipatory modes of engaging with uncertainty, and the neoliberal institutional forms they are associated with (Shore and Wright, 2015). As our autoethnographic analysis shows, personal and less explicit ways of knowing (including "feeling" and "sensing" safety through contingent and 
sometimes improvisory embodied, affective, and sensory engagements) are fundamental for researcher (and other workers') safety. This argument might not appear particularly novel to anthropologists. However when it is taken into the interdisciplinary field of OSH literatures, it provides a novel rejoinder to top down frameworks and can contribute to contemporary revisionary applied scholarship in the OSH field. Read in the context of this Special Issue, insights generated from our autoethnographic reflections offer new routes to understanding researcher safety that may prompt critical transdisciplinary discussion.

As institutional commitments to OSH frameworks (unmoored from specific disciplinary practices and understandings) increasingly frame ethnographic fieldwork, there is a need for further sustained debate on the issue of researcher safety. We are not suggesting that all ethnographers learn to be safe in the same way. But that an anthropological understanding of learning and knowing as processual, multisensory, and contingently situated show how anticipatory and adaptive ways of engaging with uncertainty tend, in practice, to be relational (rather than oppositional) to each other, for researchers as well as for workers in other fields. Consequently, there is a double implication for ethnographic practice in audit culture. Anthropologically informed ethnography offers a critical perspective and voice through which to study such forms of governance. Moreover, by contributing to applied research projects in the fields where such frameworks are developed, it also holds potential to participate in debates in the disciplines that inform the making of anticipatory cultures like that of OSH. To re-emphasize a point already made, we are not suggesting OSH guidance and policy be abandoned. Rather, we acknowledge the potential for alternative ways of knowing to be integrated (and not assumed to be oppositional) into researcher safety design. In fields beyond anthropology, there have been similar calls for contextual and reflexive learning to inform OSH approaches to practitioner and researcher safety. For example, through the greater recording and sharing of experience through debriefing and associated 
techniques like the "emotional listening" Ferguson (2009) argues for. To participate in these debates holds rich scope to inform the creative re-design of OSH guidance. It is our hope anthropology can ultimately do so in ways that may benefit - and successfully ensure the safety of - ethnographic fieldworkers working within and beyond the discipline. 


\section{References}

Adey, P., \& Anderson, B. (2011). Event and anticipation: UK civil contingencies and the space-times of decision. Environment and Planning A, 43(12), 2878-2899.

Anderson, L. (2006). Analytic autoethnography. Journal of Contemporary Ethnography, 35(4), 373-395.

Anderson, B. (2010). Preemption, precaution, preparedness: Anticipatory action and future geographies. Progress in Human Geography, 34(6), 777-798.

Bloor M., Fincham, B., \& Sampson, H., (2007). Qualiti (ncrm) commissioned inquiry into the risk to well-being of researchers in qualitative research (Report). Cardiff University. Retrieved from http://www.cf.ac.uk/socsi/qualiti/CIReport.pdf

Chang, H., Ngunjiri, F. W., \& Hernandez, K-A. C., (2013) Collaborative autoethnography. Walnut Creek: Left Coast Press.

Dickson-Swift, V., James, E. L., Kippen, S., \& Liamputtong, P., (2008). Risk to researchers in qualitative research on sensitive topics: Issues and strategies. Qualitative Health Research, 18(1), 133-144.

Ellis, C., Adams, T., \& Bochner, A., (2011). Autoethnography: an overview. Forum: Qualitative Social Research, 12(1), Retrieved from http://www.qualitativeresearch.net/index.php/fqs/article/view/1589/3096.

Evans, G., (2012). Practising participant observation: an anthropologist's account. Journal of Organizational Ethnography, 1(1), 96-106.

Ferguson, H., (2009). Performing child protection: Home visiting, movement and the struggle to reach the abused child. Child \& Family Social Work, 14(4), 471-480.

Ferguson, H., (2010). Walks, home visits and atmospheres: Risk and the everyday practices and mobilities of social work and child protection. The British Journal of Social Work, 40(4), 1100-1117. 
Grasseni, C., (2009). Introduction. Skilled visions: Between apprenticeship and standards. C. Grasseni (Ed.), Skilled Visions: Between Apprenticeship and Standards (pp.1-19). Oxford: Berghahn.

Hale, A., \& Borys, D., (2013). Working to rule, or working safely? Part 2: The management of safety rules and procedures. Safety Science, 55, 222-231.

Harris, M., (Ed.) (2007). Ways of knowing: New approaches in the anthropology of experience and learning. Oxford: Berghahn.

Harrison, R., (2013). Heritage: Critical approaches. London: Routledge.

Hayano, D., (1979). Auto-ethnography - paradigms, problems, and prospects. Human Organization, 38(1), 99-104.

Ingold, T., (2011a). The perception of the wnvironment: Essays on livelihood, dwelling, and skill (reissued with a new preface). Abingdon: Routledge.

Ingold, T., (2011b). Being alive: Essays on movement, knowledge, and description. Abingdon: Routledge.

Ingold ,T., (2013). Making: Anthropology, archaeology, art and architecture. Abingdon: Routledge.

Knox, H., \& Harvey, P., (2011). Anticipating harm: Regulation and irregularity on a road construction project in the Peruvian Andes. Theory, Culture Society, 28(6), 142163.

Lederman, R., (2007). Educate your IRB: An experiment in cross-disciplinary communication. Anthropology News, 48(6), 33-34.

Lingard, H., Pink, S., Harley, J., \& Edirisinghe, R., (2015). Looking and learning: Using participatory video to improve health and safety in the construction industry. Construction Management and Economics, 33(9), 740-751

Macdonald, S., (2009). Making ethics. M. Melhuus, J. Mitchell, \& H. Wulff (Eds.), 
Ethnographic practice in the present (EASA series, pp.80-94). Oxford: Berghahn.

Marchand, T., (2010). Making knowledge: explorations of the indissoluble relation between minds, bodies, and environment. Journal of the Royal Anthropological Institute, 16(Issue Supplement s1), S1-S21.

Meskell, L., \& Pels, P., (2005). Embedding Ethics. Oxford: Berg.

Moreno, E., (1995). Rape in the field: Reflections of a survivor. D. Kuklick \& M. Wilson (Eds.), Taboo: Sex, Identity and Erotic Subjectivity in Anthropological Fieldwork (pp. 219-250). New York: Routledge.

Pink, S., (2007). Walking with video. Visual Studies, 22(3), 240-252.

Pink, S., \& Morgan, J., (2013). Short-term ethnography: Intense routes to knowing. Symbolic Interaction, 36(3): 351-361.

Pink, S., Morgan, J., \& Dainty, A., (2014a). Safety in movement: mobile workers, mobile media. Mobile Media and Communication, 2(3), 335-351.

Pink, S., Morgan, J., \& Dainty, A., (2014b). The safe hand: Gels, water, gloves and the materiality of tactile knowing. Journal of Material Culture, 19(4), 425-442.

Pink, S., Morgan, J., \& Dainty, A., (2015). Other people's homes as sites of uncertainty: Ways of knowing and being safe. Environment and Planning A, 47, 450-464.

Powell, M., Glendinning, S., Broto, VC., Dewberry, E., \& Walsh, C., (2014). Shaped by shock: staff on the emergency department 'shop floor'. Anthropology in Action, 21(2), 14-22.

Power, M., (2004). The risk management of everything. Rethinking the politics of uncertainty. DEMOS: London. Retrieved from: http://www.demos.co.uk/files/riskmanagementofeverything.pdf Samimian-Darash, L., \& Rabinow, P., (Eds.) (2015). Modes of uncertainty: Anthropological cases. London: The University of Chicago Press. 
Shore, C., \& Wright, S., (1999). Audit culture and anthropology: neo-liberalism in British higher education. The Journal of the Royal Anthropological Institute, 5(4), $557-575$

Shore, C., \& Wright, S., (2000). Coercive accountability: The rise of audit culture in higher education. M. Strathern (Ed.), Audit Cultures: Anthropological Studies in Accountability, Ethics, and the Academy (pp.57-89). Abingdon: Routledge.

Shore, C., \& Wright, S., (2015). Governing by numbers: Audit culture, rankings and the new world order. Social Anthropology, 23(1), 22-28.

Sluka, J., (2012). Reflections on managing danger in fieldwork: Dangerous anthropology in Belfast. A. Robbens \& J. Sluka J (Eds.), Ethnographic Fieldwork: An Anthropological Reader (pp.283-295). Chichester: Wiley-Blackwell.

Strathern, M., (2000) Accountability... and ethnography. M. Strathern (Ed.), Audit cultures: Anthropological studies in accountability, ethics and the academy (pp.279304). Abingdon: Routledge. 